\title{
Transparent-Conductive-Oxide-Free Front Contacts for High Efficiency Silicon Heterojunction Solar Cells
}

Shenghao Li ( $\nabla$ s.li@fz-juelich.de )

Research Center Juelich https://orcid.org/0000-0002-3196-7981

Manuel Pomaska

Forschungszentrum Jülich

Andreas Lambertz

Forschungszentrum Jülich

Weiyuan Duan

Forschungszentrum Jülich

Karsten Bittkau

Research Center Juelich

Depeng Qiu

Research Center Juelich

Zhirong Yao

Research Center Juelich

Martina Luysberg

Forschungszentrum Jülich $\mathrm{GmbH}$

Paul Steuter

Research Center Juelich

Malte Koehler

Forschungszentrum Jülich https://orcid.org/0000-0002-4869-4131

Kaifu Qiu

Research Center Juelich

Ruijiang Hong

Sun Yat-sen University

Hui Shen

Sun Yat-sen University

Friedhelm Finger

Forschungszentrum Jülich $\mathrm{GmbH}$

Thomas Kirchartz

Forschungszentrum Jülich https://orcid.org/0000-0002-6954-8213

Uwe Rau 
Research Center Juelich

\section{Kaining Ding}

Forschungszentrum Jülich GmbH https://orcid.org/0000-0003-0329-5951

\section{Article}

Keywords: Conductance of Heterojunction Thin Films, Efficient Carrier Collection, Lateral Conduction, Deterioration of the Passivation Quality, Ozone Treatment

Posted Date: November 11th, 2020

DOI: https://doi.org/10.21203/rs.3.rs-97106/v1

License: (c) (1) This work is licensed under a Creative Commons Attribution 4.0 International License. Read Full License

Version of Record: A version of this preprint was published at Joule on June 1st, 2021. See the published version at https://doi.org/10.1016/j.joule.2021.04.004. 


\title{
Transparent-Conductive-Oxide-Free Front Contacts for High Efficiency Silicon Heterojunction Solar Cells
}

Shenghao $\mathrm{Li}^{1,2}$, Manuel Pomaska ${ }^{1}$, Andreas Lambertz ${ }^{1}$, Weiyuan Duan ${ }^{1}$, Karsten Bittkau ${ }^{1}$, Depeng Qiu ${ }^{1,3}$, Zhirong Yao, ${ }^{1,2}$, Martina Luysberg ${ }^{4}$, Paul Steuter ${ }^{1,3}$, Malte Köhler ${ }^{1,3}$, Kaifu Qiu $^{1,2}$, Ruijiang Hong ${ }^{2}$, Hui Shen ${ }^{2,5}$, Friedhelm Finger ${ }^{1}$, Thomas Kirchartz ${ }^{1,6}$, Uwe Rau ${ }^{1,3}$ and Kaining Ding ${ }^{1}$

${ }^{1}$ IEK-5 Photovoltaik, Forschungszentrum Jülich, 52425 Jülich, Germany

${ }^{2}$ Institute for Solar Energy Systems, Guangdong Provincial Key Laboratory of Photovoltaic Technology, School of Physics, Sun Yat-Sen University, 510006 Guangzhou, China

${ }^{3}$ Faculty of Electrical Engineering and Information Technology, RWTH Aachen University, Mies-van-derRohe-Straße 15, 52074 Aachen, Germany

${ }^{4}$ Ernst Ruska-Centre for Microscopy and Spectroscopy with Electrons, Forschungszentrum Jülich, 52425 Jülich, Germany

${ }^{5}$ Jiangsu Collaborative Innovation Center of Photovoltaic Science and Engineering, Changzhou University, 213164 Changzhou, China

${ }^{6}$ Faculty of Engineering and CENIDE, University of Duisburg-Essen, Carl-Benz-Str. 199, 47057 Duisburg, Germany

\begin{abstract}
In order to compensate the insufficient conductance of heterojunction thin films, transparent conductive oxides (TCO) have been used for decades in both-sides contacted crystalline silicon heterojunction $(\mathrm{SHJ})$ solar cells to provide lateral conduction for efficient carrier collection. In this work, we substitute the TCO layers by utilizing the lateral conduction of c-Si absorber, thereby enabling a TCO-free design. A series resistance of $0.32 \Omega \mathrm{cm}^{2}$ and a fill factor of $80.7 \%$ were measured for a TCO-free back-junction SHJ solar cell with a conventional finger pitch of $1.8 \mathrm{~mm}$, thereby proving that relying on lateral conduction in the c-Si bulk is compatible with low series resistances. Achieving high efficiencies in SHJ solar cells with TCO-free front contacts requires suppressing deterioration of the passivation quality induced by direct metal-a-Si:H contacts and in-diffusion of metal into the a-Si:H layer. We show that an ozone treatment at the a-Si:H/metal interface suppresses the metal diffusion and improves the passivation without increasing the
\end{abstract}


contact resistivity. SHJ solar cells with TCO-free front contacts and ozone treatment achieve efficiencies of $>22 \%$.

\section{Introduction}

One of the fundamental challenges in the design of both sides contacted crystalline Si solar cells is the development of a contacting scheme that combines a highly conductive front contact with negligible parasitic absorption losses. The solution to this challenge involves the combination of highly conductive, opaque and locally applied materials (a metal grid) with slightly less conductive, fairly transparent layers that fully cover the front surface of the solar cell and facilitate lateral conduction to the nearest grid finger. For high temperature diffused junction solar cells, the conductive layer is the heavily doped emitter, which shows a sheet resistance typically ranging from $40 \Omega / \square$ to $100 \Omega / \square^{1}$. Optimization of the diffused emitter has dealt with the trade-off between contact resistivity with metal grids and Auger recombination (increases quadratically with doping density $)^{2}$. This compromise leads to fill factor $(F F)$ losses for lower doping densities and opencircuit voltage $\left(V_{\mathrm{oc}}\right)$ losses for higher doping densities. The selective emitter reliefs this trade-off by reducing the local contact resistivity at a cost of minor increase in recombination ${ }^{3}$.

Silicon heterojunction (SHJ) solar cells completely avoid the highly doped diffused emitter regions by using chemical vapour deposited amorphous Si layers to form charge-selective junctions at both sides of the wafer. However, given that the amorphous contact layers are very thin and have comparably poor lateral conductivities, additional transparent conductive oxide layers have always been used since the development of SHJ solar cells featuring doped a$\mathrm{Si}: H /$ intrinsic a-Si:H layer stacks in $1991^{4}$. While the TCO ensures sufficient lateral conductivity, it has a good but not perfect transmission that leads to losses in short circuit current density $\left(J_{\mathrm{sc}}\right)$. In addition, the most commonly used TCO is indium tin oxide (ITO) which is economically problematic because of the high price and supply risk of indium ${ }^{5-7}$. Given that the reported highest open-circuit voltage is $727.6 \mathrm{mV}$ for a diffused junction solar cell (with a very low doping density in the emitter resulting in a sheet resistance of $300 \Omega / \square)^{8}$, open-circuit voltages of $>750 \mathrm{mV}$ are only possible with silicon heterojunction solar cells ${ }^{9,10}$. Therefore, the future of crystalline $\mathrm{Si}$ photovoltaics would benefit greatly from any solution to circumvent the parasitic absorption in the TCOs and the use of indium.

With the recent development of back side emitter SHJ solar cells ${ }^{11-13}$, the opportunity opens up 
to omit at least the front side TCO as shown schematically in Fig. 1. In the design shown in Fig. 1a (front side emitter) ${ }^{4,14}$, holes would have to diffuse in the n-type wafer to the interface with the ITO from where efficient hole transport would happen to the metal finger. Removing the ITO in such a design would require the metal grid spacing to be much less than the diffusion length of holes in the n-type wafer. If, however, the junction is at the back as shown in Fig. 1b, the holes as minority carriers would diffuse to the back contact which is fully metallized. The electrons would drift to the front contact, where they would be collected also without the use of an ITO layer (Fig. 1c), because they are the majority carriers in the n-type wafer. Ideally, the scenario shown in Fig. 1c should enable efficient silicon solar cells with the potential downside of added resistive losses due to the lateral conduction of electrons in the n-type wafer as opposed to the ITO as shown in Fig. 1b. A further concern would be the validity of the assumption that electron collection in the n-type wafer is still efficient at the maximum power point (MPP) of the solar cell, where for typical bulk doping densities of $N_{\mathrm{d}}=4.5 \times 10^{15} \mathrm{~cm}^{-3}(1.09 \Omega \mathrm{cm})$ hole concentrations become comparable to electron concentrations. In Fig. 2a we show using numerical simulations with Quokka3 that the one-sun excess carrier concentration $(\Delta n)$ of a rear junction SHJ solar cell at maximum power point is around $2 \times 10^{15} \mathrm{~cm}^{-3}$. Using this value, the sheet resistances of c-Si absorber under illumination are calculated with the following equation:

$$
\begin{aligned}
& R_{\text {sheet,c-Si }}=\frac{\rho}{d}=\frac{\left(q \mu_{\mathrm{e}} n_{\mathrm{e}}+q \mu_{\mathrm{h}} n_{\mathrm{h}}\right)^{-1}}{d} \\
& R_{\text {sheet,electron }}=\frac{\left(q \mu_{\mathrm{e}} n_{\mathrm{e}}\right)^{-1}}{d}, R_{\text {sheet,hole }}=\frac{\left(q \mu_{\mathrm{h}} n_{\mathrm{h}}\right)^{-1}}{d}
\end{aligned}
$$

where $d$ is the wafer thickness, $q$ is the elementary charge, $\mu$ is the mobility and $n$ is the carrier density of the respective carriers $\left(n_{\mathrm{e}}=n_{\mathrm{d}}+\Delta n\right.$ while $n_{\mathrm{h}} \approx \Delta n$ under illumination). The low sheet resistance of $46 \Omega / \square$ for electrons at $N_{\mathrm{d}}=4.5 \times 10^{15} \mathrm{~cm}^{-3}(1.09 \Omega \mathrm{cm})$ suggests good lateral conductance of majority carriers, while the sheet resistance of holes is higher than $400 \Omega / \square$ (Fig. 2c). While Fig. 2 suggests that there is a potential to make efficient SHJ solar cells without a TCO at the front side, the necessity for efficient photon reflection at the back contact still requires a back side TCO. This is due to the fact that TCO/metal combinations are substantially better mirrors than bare metal contacts. 


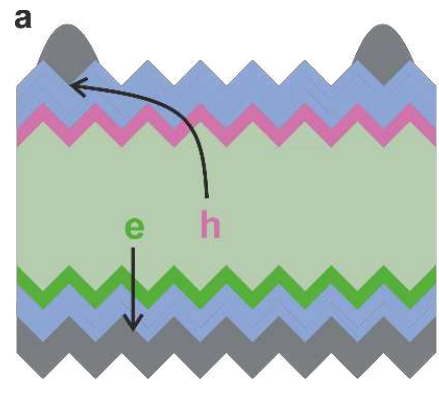

TCO

a-Si:H ( $\left.\mathbf{p}^{+}\right) / \mathrm{a}-\mathrm{Si}: \mathrm{H}(\mathrm{i})$

c-Si (n)

a-Si:H (i)/a-Si:H $\left(\mathbf{n}^{+}\right)$

metal contact

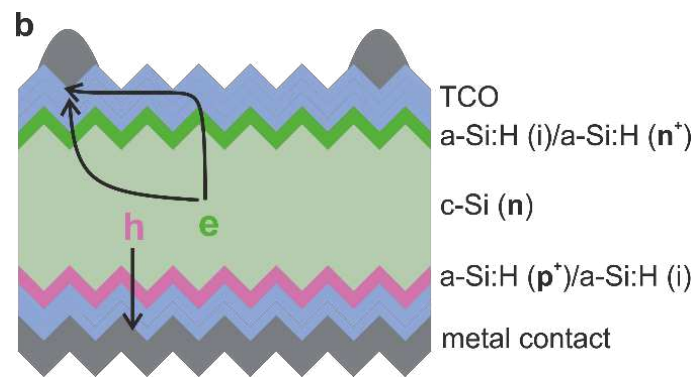

c

ARC

a-Si:H (i)/a-Si:H $\left(\mathbf{n}^{+}\right)$

$\mathrm{c}-\mathrm{Si}(\mathbf{n})$

a-Si:H ( $\left.\mathbf{p}^{+}\right) / a-S i: H(i)$

metal contact

Fig. 1 | Illustration of different SHJ solar cell structures and the path for charge carriers to electrodes. a, Sketch of conventional SHJ solar cell structure with a front emitter. $\mathbf{b}$, Conventional SHJ solar cell structure with a rear emitter. c, Rear emitter SHJ solar cells using only the absorber for lateral conduction. SiN $x_{x}$ layers are used in the present work as anti-reflection coatings (ARC).
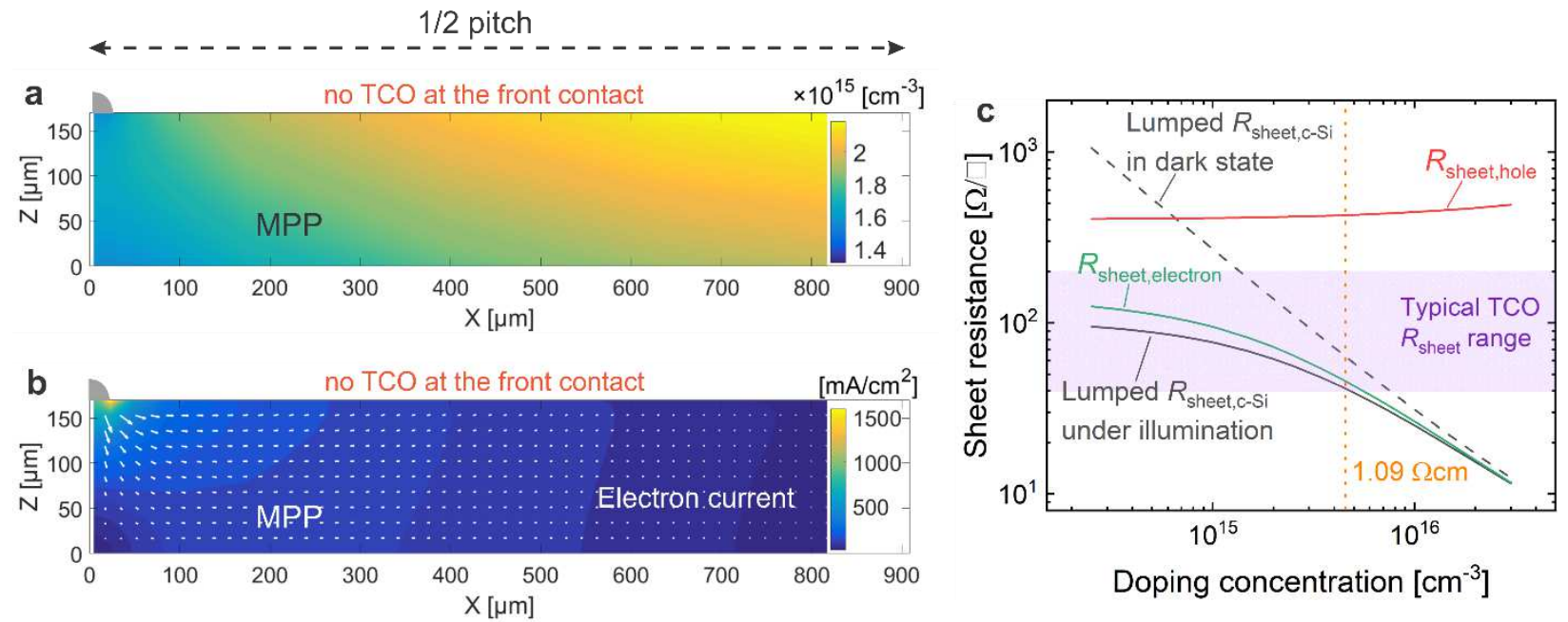

Fig. 2 | Carrier transport in c-Si bulk. a, Cross-section image of one-sun excess carrier distribution $(\Delta n=\Delta p)$ in a rear junction SHJ solar cell without front side TCO layer at maximum power point. b, Cross-section image of electron current density in a rear junction SHJ solar cell without front side TCO layer under one-sun illumination at maximum power point. c, Sheet resistance of phosphorus doped c-Si wafer with a thickness of $170 \mu \mathrm{m}$. The dashed line indicates values without illumination and the solid lines indicates values under illumination. The excess carrier concentration under illumination is set as $2 \times 10^{15} \mathrm{~cm}^{-3}$, which is estimated from fig. $2 \mathrm{a}$. The silicon wafer resistivity is $1.09 \Omega \mathrm{cm}$ in this work which is marked by the dotted line. These results show that majority carriers (electron) are ready for lateral collection in the c-Si bulk. 
Here, we show the feasibility of a TCO-free design at the front contact of a SHJ solar cell showing efficiencies $>22 \%$. These high efficiencies are enabled by the excellent majority carrier conductivity in the c-Si absorber under illumination, leading to a low series resistance of 0.32 $\Omega \mathrm{cm}^{2}$ and a fill factor of $80.7 \%$. The conduction of the above-mentioned SHJ solar cell is then investigated by electroluminescence (EL) imaging and illumination variation. As the TCO layer is removed, we investigated the direct metal contacts with a-Si:H layer stacks to avoid the passivation degradation. At last, the future potential of removing front side TCO for high efficiency SHJ solar cell is discussed.

\section{Proof-of-concept TCO-free SHJ solar cells}

Front side TCO-free and completely TCO-free SHJ solar cells were fabricated with the geometry shown in Fig. 1c to verify the lateral conduction of majority carriers in c-Si absorber. Phosphorus doped n-type silicon wafers with a resistivity of $1.09 \Omega \mathrm{cm}$ and a thickness of $170 \mu \mathrm{m}$ were used. The pitch of fingers was $1.8 \mathrm{~mm}$ which is commonly used in SHJ solar cells. Without TCO as buffer layers, the direct metal/a-Si:H contact reduces the passivation quality, which can be avoided by increasing the a-Si:H layer thickness. Solar cell performances with different a-Si:H layer thickness are shown in Fig. 3. For front side TCO-free SHJ solar cells, the highest fill factor of 79.8\% was measured (Fig. 3c), which illustrates a good lateral conductance of c-Si absorber can be achieved without TCO front contact. This is also proven by the both sides TCO-free SHJ solar cells, which achieves a fill factor of $80.7 \%$ in Fig. $3 \mathrm{~h}$ and a series resistance of $0.32 \Omega \mathrm{cm}^{2}$ in Fig. 3i. It is worth noting that the fill factor improvement from front side TCO-free to both sides TCOfree solar cells originates from the reduced contact resistivity on the rear side. The $30 \mathrm{~nm}$ a$\mathrm{Si}: \mathrm{H}\left(\mathrm{p}^{+}\right) /$metal contact resistivity is $0.15 \Omega \mathrm{cm}^{2}$ while the a-Si: $\mathrm{H}\left(\mathrm{p}^{+}\right) / \mathrm{TCO}$ contact resistivity is 0.3 $\Omega \mathrm{cm}^{2}$.

As shown in Fig. 3a, the open-circuit voltage increases from $709.0 \pm 1.5 \mathrm{mV}$ to $721.1 \pm 0.8 \mathrm{mV}$ when the thickness of a-Si:H $\left(\mathrm{n}^{+}\right)$layer increases from $7.5 \mathrm{~nm}$ to $30 \mathrm{~nm}$ in front side TCO-free solar cells. When the SHJ solar cell is completely TCO-free and the a-Si:H $\left(\mathrm{n}^{+}\right)$layer is $15 \mathrm{~nm}$ thick, the open-circuit voltage increases from $638.3 \pm 7.9 \mathrm{mV}$ to over $710.2 \pm 5.7 \mathrm{mV}$ as the thickness of a-Si:H $\left(\mathrm{p}^{+}\right)$layer increases from $7.5 \mathrm{~nm}$ to $60 \mathrm{~nm}$ (Fig. 3f). These results show that the passivation is deteriorated when metal is directly fabricated on the doped a-Si:H layers, and increasing the doped a-Si:H layer thickness relieves the deterioration. However, increasing the thickness of a-Si:H $\left(\mathrm{n}^{+}\right)$thin film in the front surface of SHJ solar cell also increases the parasitic 
absorption of a-Si:H $\left(\mathrm{n}^{+}\right)$layer and reduces the short-circuit current density, as shown in Fig. $3 b$. On the other hand, the short-circuit current density of both sides TCO-free is lower than that of front side TCO-free solar cell, which is due to the low back reflection of the rear metal surface. More details about the optical spectra are shown in Fig. S4.

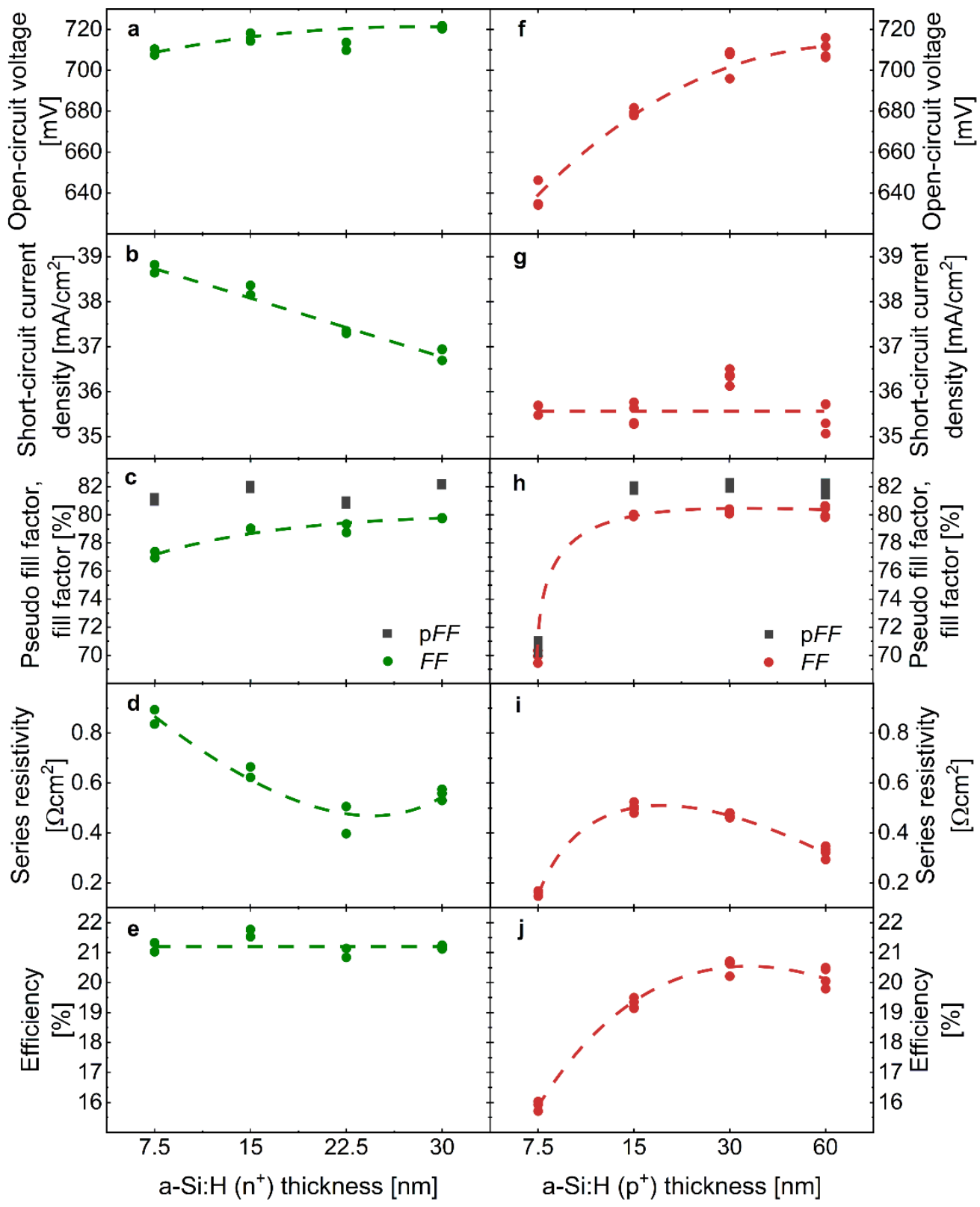

Fig. 3 | Performance of SHJ solar cells without TCO as lateral conduction layer. a-e, Front side TCO-free solar cell performance with different a-Si:H $\left(n^{+}\right)$layer thicknesses. $\mathbf{f - j}$, Both side TCO-free solar cell performance with different a-Si:H $\left(\mathrm{p}^{+}\right)$layer thicknesses. For both side TCO-free solar cells, the a-Si:H $\left(\mathrm{n}^{+}\right)$layer thickness was $15 \mathrm{~nm}$. The dashed lines are guides to the eye.

The electroluminescence image of a front side TCO-free solar cell is shown in Fig. 4a. The 
image shows homogeneous luminescence intensity between fingers with a pitch of $1.8 \mathrm{~mm}$. The local diode voltage mapping is extracted from the electroluminescence images (Fig. 4b) ${ }^{15}$, which shows a homogeneous diode voltage distribution with a fluctuation of about $1 \mathrm{mV}$. No obvious diode voltage change between the fingers is observed indicating a good lateral conductance without $\mathrm{TCO}^{16-18}$.
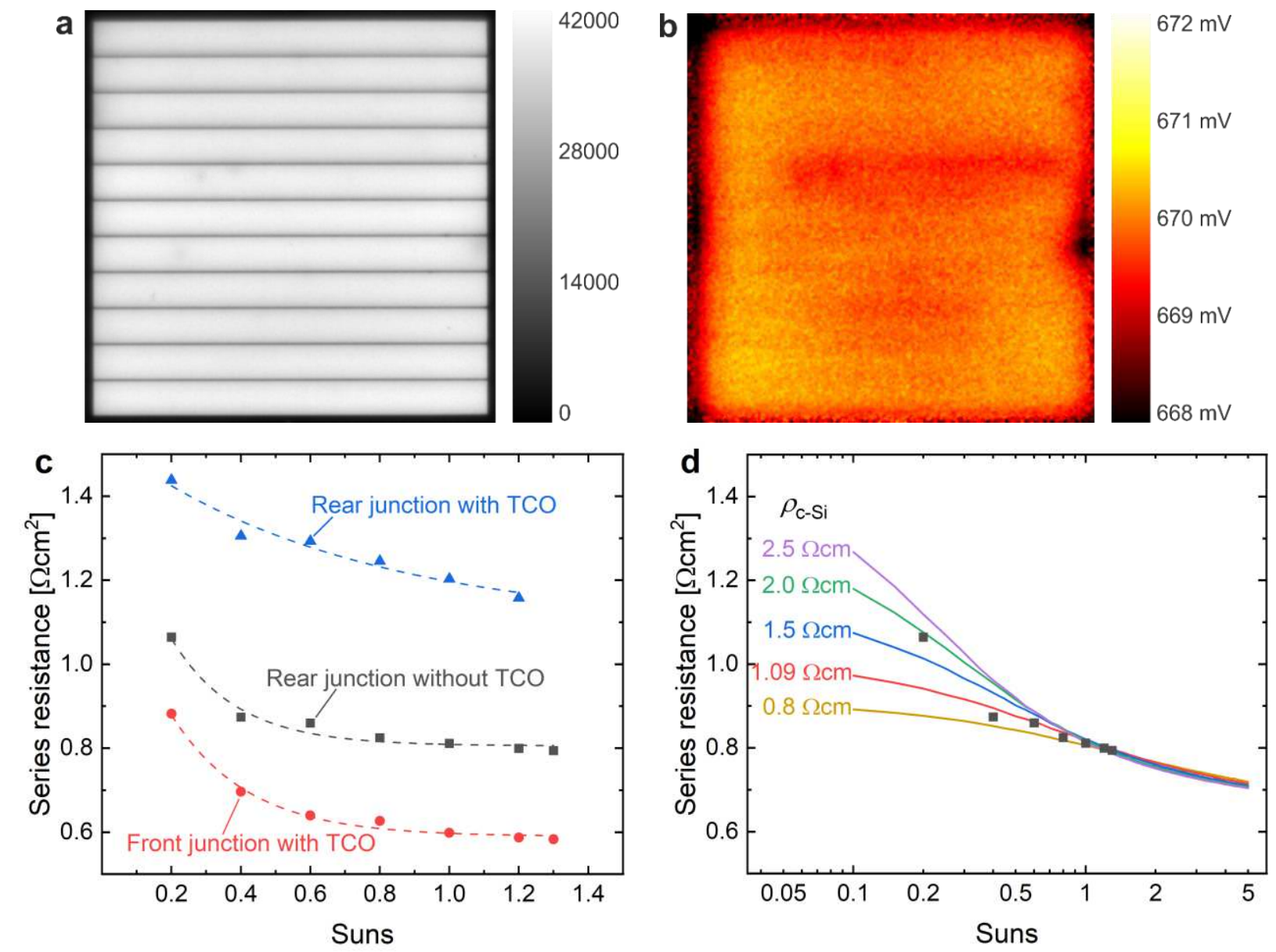

Fig. 4 | Conduction properties of SHJ solar cells without TCO front contact. a, EL image of a front side TCO-free SHJ solar cell. $\mathbf{b}$, Local voltage distribution extracted from EL images. c, Measured series resistance versus illumination intensity for different $\mathrm{SHJ}$ solar cells. $\mathbf{d}$, Simulated series resistance versus illumination intensity for rear junction TCO-free SHJ solar cells with different wafer resistivities. The black dots in Fig. $4 \mathrm{~d}$ is the same data as the black dots in Fig. 4c. The simulated series resistance was calculated from the integral of the resistive losses in the model, which is not measurable, while the experimental series resistance was extracted from dark-light $\mathrm{J}-\mathrm{V}$ method ${ }^{19}$.

In Fig. $4 \mathrm{c}$ the lateral conduction of TCO-free front contact cells is further analyzed by extracting the series resistance (dark-light $J-V$ method ${ }^{19}$ ) under different illumination intensity for SHJ solar cells with and without TCO in the front surface. For the rear junction solar cell without front TCO, 
the series resistance reduces from $1.06 \Omega \mathrm{cm}^{2}$ to $0.79 \Omega \mathrm{cm}^{2}$ when the illumination intensity increases from 0.2 suns to 1.3 suns, which indicates an increased conduction of c-Si bulk with an increasing injection level. As a comparison, both front and rear junction reference cell with TCO also show a similar trend that series resistance reduces as illumination increases. The Quokka3 simulation in Fig. S3 shows a similar trend as the experimental results. The finding of light intensity dependent series resistances indicates that even in a front junction solar cell, the absorber conduction takes part in the front side lateral collection. This is verified in the carrier distribution simulation shown in Fig. S2. Fig. 4d shows the fit of simulation results to the experimental results for rear junction SHJ solar cells without front TCO, which indicates that the variation of series resistance increases as the bulk resistivity increases.

\section{Direct metal/a-Si:H contacts}

When TCO is removed from SHJ solar cells, the metal grids form a direct contact with a-Si:H thin film stacks. To enable a high performance TCO-free SHJ solar cell, two issues have to be solved for the metal/a-Si:H direct contacts. The first issue is that the contacts must be Ohmic contacts, which is realized by using titanium as the contact metal with a-Si:H stacks in this work (Fig. S6). The second issue is that without TCO as buffer layer, fabricating metals directly on a$\mathrm{Si}: \mathrm{H}$ stacks causes a degradation on the passivation of the solar cell ${ }^{20}$. The metal/a-Si:H contact was investigated by performing scanning transmission electron microscopy (STEM) on the metal/a-Si:H interface. As shown in Fig. 5a and 5c, instead of forming a sharp metal/a-Si:H interface, metals diffuse into the a-Si:H layers. When the metal atoms penetrate through the a-Si:H thin film and reach the c-Si surface, degradation in passivation occurs due to the increased Shockley-Read-Hall recombination ${ }^{21,22}$. The diffusion shown in the STEM image can be as deep as $50 \mathrm{~nm}$ from the contact interface, which indicates that an a-Si:H thickness of over $50 \mathrm{~nm}$ is needed to avoid the metal-induced degradation. This observation agrees with the solar cell results in Fig. 3. The best open-circuit voltage is $715.9 \mathrm{mV}$ with $60 \mathrm{~nm}$ a-Si:H $\left(\mathrm{p}^{+}\right) /$metal contact in Fig. 3f, which is comparable to $718.2 \mathrm{mV}$ with rear $\mathrm{TCO} /$ metal contact in Fig. 3a.

In order to prevent the metal diffusion, a thin $\mathrm{SiO}_{\mathrm{x}}$ layer $(1.6 \mathrm{~nm}$ on polished silicon wafer by spectroscopic ellipsometer) was added to the metal and a-Si:H interface. To this end, ozone oxidation was performed on the surface of a-Si:H layers before the fabrication of metal stacks. The STEM images are shown in Fig. 5b and 5d for comparison. Compared to Fig. 5a, the diffusion is prominently inhibited by the ozone oxidation in the interface, as shown in Fig. 5b. A clear interface 
between the Ti and a-Si:H layer is shown in Fig. 5d. There is still a small fraction of diffusion as shown in Fig. 5d. However, the diffusion area is much smaller and the penetrating depth is less than $10 \mathrm{~nm}$.

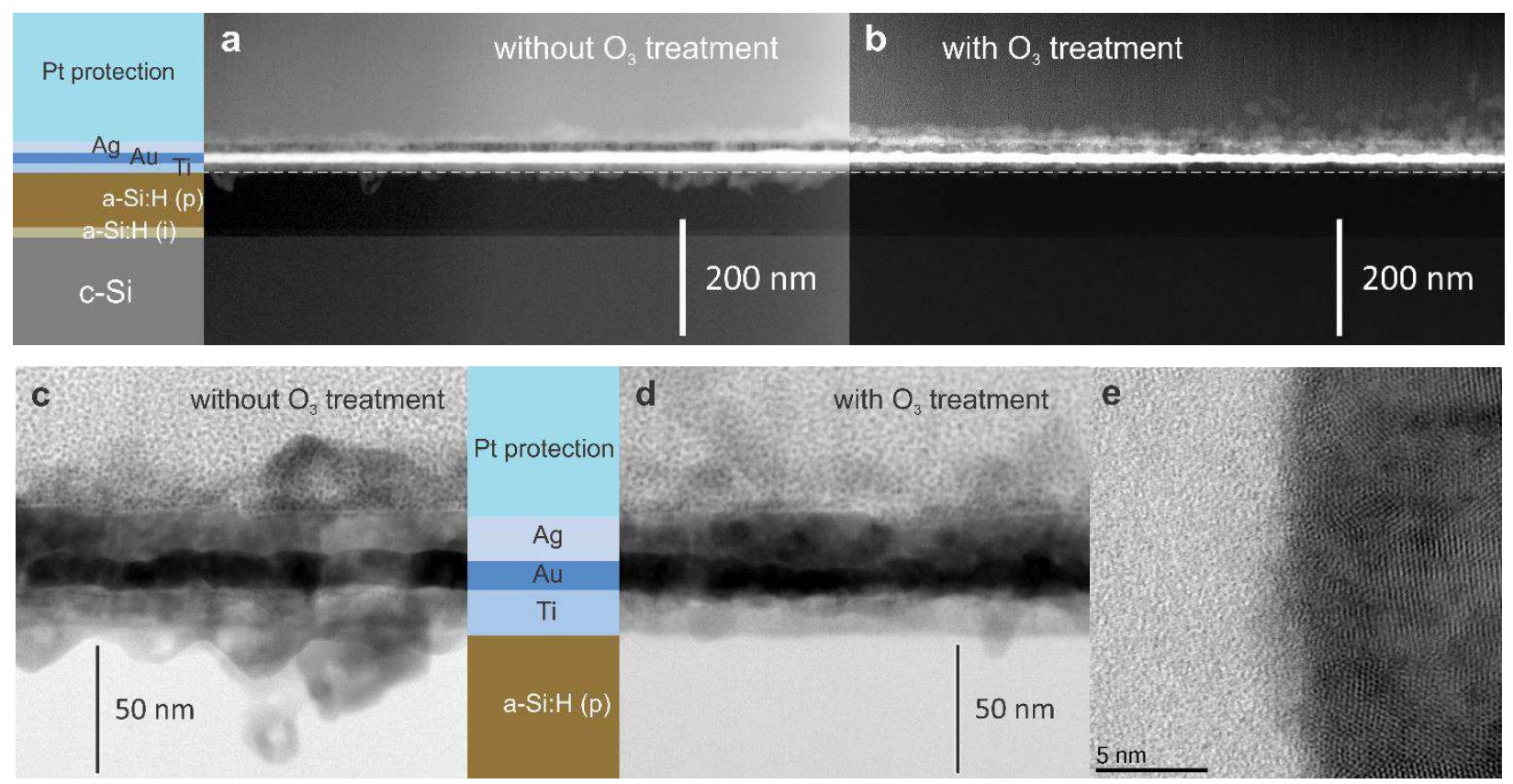

FIG. 5 | STEM images of the metal and a-Si:H interfaces. a-b, Dark field (DF) image of metal/a-Si:H interface without and with ozone treatment. c-d, Bright field (BF) image of metal/a-Si:H interface without and with ozone treatment. e, High-resolution BF image of metal/a-Si:H interface with ozone treatment. The STEM images show that metal diffusion leads to passivation deterioration when there is no buffer layer such as TCO in the metal/a-Si:H contact. However, an ozone oxidation on the a-Si:H layers before metallization prominently restricts the metal diffusion in the metal/a-Si:H contact.

Although the ozone oxidation provides a good barrier for the metal, the thin $\mathrm{SiO}_{\mathrm{x}}$ was not clearly seen in the Ti/a-Si:H interface, as shown in Fig. 5e. On the other hand, secondary ion mass spectrometry measurement shows extra oxygen signal at the Ti/a-Si:H interface (Fig. S7). It is reported that titanium reacts with the silicon oxide during evaporation process ${ }^{23}$ and forms contacts with good adhesion. The contact resistivity between metal stacks and doped a-Si:H layers shows no prominent difference with and without ozone treatment (Fig. S6), which may be also due to the $\mathrm{Ti}^{-} \mathrm{SiO}_{\mathrm{x}}$ reaction.

The front side TCO-free SHJ solar cell performance with and without ozone oxidation are shown in Fig. 6a. By applying ozone oxidation, the open-circuit voltage increases by $11 \mathrm{mV}$. An improved fill factor of $79.9 \%$ was measured. An efficiency of $22.3 \%$ was measured in the front 
side TCO-free SHJ solar cell under standard test conditions (AM1.5G, $\left.1000 \mathrm{~W} \cdot \mathrm{m}^{-2}, 25^{\circ} \mathrm{C}\right)$. The integration of ozone oxidation to the fabrication of SHJ solar cells is discussed in the supplementary information. In Fig. 6b the external quantum efficiency comparison (do not contain fingers) shows a prominently improvement by removing TCO parasitic absorption. An increased current density of around $1 \mathrm{~mA} / \mathrm{cm}^{2}$ is demonstrated. The difference between external quantum efficiency and short-circuit current density, which is attributed to the metal fingers, is discussed in supplementary information Fig. S5.
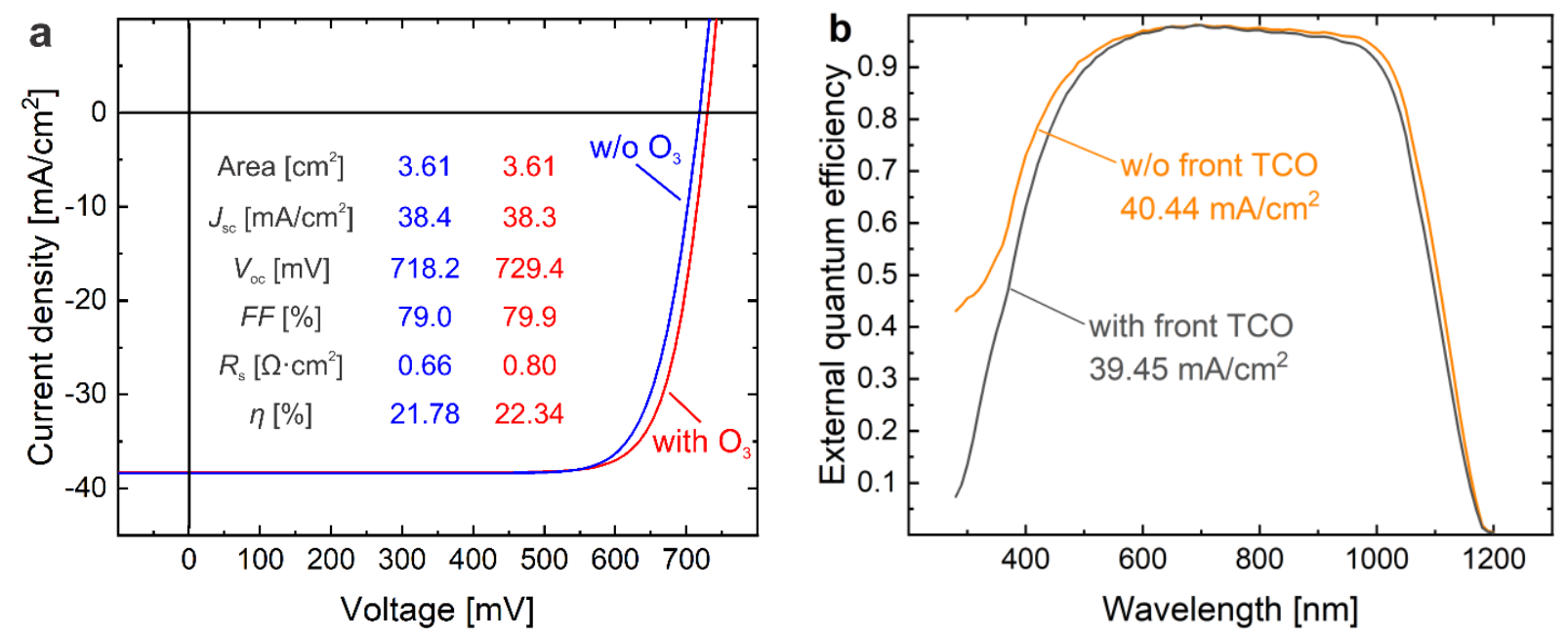

FIG. 6 Characterization of front side TCO-free solar cells. a, Comparison between J-V performance with and without $\mathrm{O}_{3}$ oxidation as metal diffusion barrier. $\mathbf{b}$, External quantum efficiency comparison between front-side TCO-free solar cells and standard SHJ solar cells with front TCO. It should be noted that the a-Si:H(n) layer thickness is $15 \mathrm{~nm}$ for fig. $6 a$ and $7.5 \mathrm{~nm}$ for fig. 6b. An improved external quantum efficiency is shown by removing TCO layer in the front side, giving rise to an increase of $1 \mathrm{~mA} / \mathrm{cm}^{2}$ in current density.

\section{Potential of substituting TCO layer by lateral c-Si bulk conduction}

Although TCO is removed and the lateral conduction between fingers relies only on the c-Si absorber, high-quality carrier collection is achieved with a small series resistance of $0.32 \Omega \mathrm{cm}^{2}$ and a high fill factor of $80.7 \%$ in completely TCO-free SHJ solar cells. To compare the lateral conduction of TCO-free SHJ solar cell and conventional SHJ solar cell with TCOs, Quokka3 ${ }^{24-26}$ was used to simulate the solar cell performances and the results are shown in Fig. 7a. The series resistance $\left(R_{\mathrm{S}}\right)$ increases from 0.35 to $0.39 \Omega \mathrm{cm}^{2}$ when the TCO changes from $40 \Omega / \square$ to without TCO, giving rise to a decrease of fill factor $(F F)$ from $83.7 \%$ to $83.2 \%$. The result shows that with the help of conductive c-Si bulk materials, removing the TCO results in only a minor increase of $0.04 \Omega \mathrm{cm}^{2}$ in series resistance. What is more, the TCO-free design can also be applied on silicon 
wafers as thin as $30 \mu \mathrm{m}$ with a series resistance lower than $0.6 \Omega \mathrm{cm}^{2}$ (discussed in supplementary information Fig. S9).

On the other hand, for the minor cost of $0.04 \Omega \mathrm{cm}^{2}$ in series resistance, the parasitic absorption caused by the front side TCO is removed. Optical simulation by OPAL2 in Fig. 7b shows that there is a reduced parasitic absorption of $0.88 \mathrm{~mA} / \mathrm{cm}^{2}$ and a reduced reflection of $0.21 \mathrm{~mA} / \mathrm{cm}^{2}$ by replacing ITO by $\mathrm{SiN}_{\mathrm{x}}$ as antireflection coatings. This result fits well to the experimental results in Fig. 6b. It also suggests that when the parasitic absorption loss caused by ITO is removed, the remaining parasitic absorption loss is mainly caused by a-Si:H thin film.
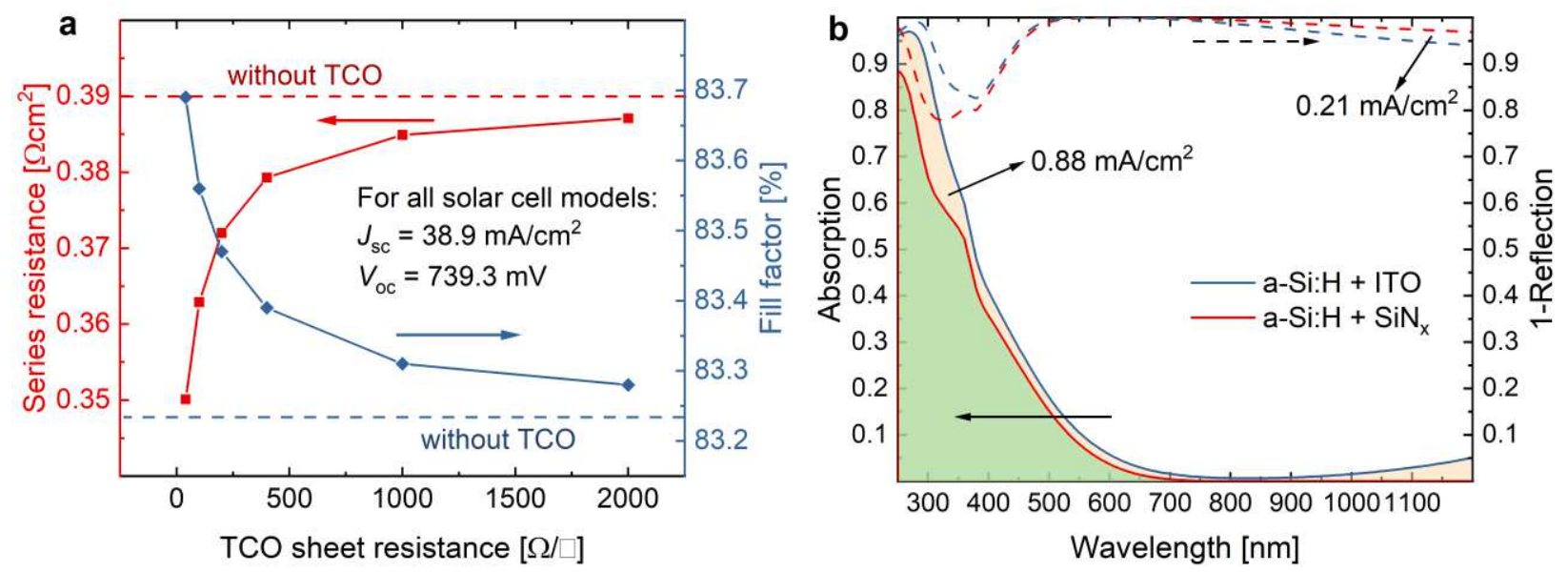

Fig. 7 | Comparison for SHJ solar cells with and without front-side TCO. a, Simulated performance of rear junction SHJ solar cell with and without front TCO. Solar cell performances with different TCO sheet resistance in the front surface are shown in dots and solid lines. The solar cell performances without front side TCO are shown by the dash line. The optical performance, surface passivation qualities and metal contact resistivities were kept the same with and without TCO to focus only on the lateral electrical transport properties. $\mathbf{b}$, Simulated absorption and 1-reflection spectra using ITO and $\mathrm{SiN}_{\mathrm{x}}$ as antireflection coating, respectively. By replacing ITO with $\mathrm{SiN}_{\mathrm{x}}$, the absorption loss is reduced by $0.88 \mathrm{~mA} / \mathrm{cm}^{2}$ and the reflection loss is reduced by $0.21 \mathrm{~mA} / \mathrm{cm}^{2}$.

When the TCO layer is removed, the sputter damage ${ }^{27}$ can also be avoided in TCO-free SHJ solar cells. However, the metal/a-Si:H contact introduces damage to the passivation, which can be solved by inhibiting the metal diffusion into the c-Si surface. In this work, an open-circuit voltage of $731 \mathrm{mV}$ was achieved by applying ozone oxidation at the metal/a-Si:H interface without increasing the contact resistivity.

Table 1 shows the comparison between SHJ solar cells with and without TCO. By substituting TCO layers with lateral bulk collection we are able to 1) solve the rely on indium in SHJ solar cell and 2) avoid the dilemma of transparency and conductance in TCO layers. In this work two tasks 
are achieved: 1) low series resistance without TCO, and 2) good metal/a-Si:H contact by an oxidation treatment at the interface. Further development that contributes to TCO-free SHJ solar cells could be replacing rear side TCO by proper back reflection design ${ }^{28,29}$ and developing more transparent front-side heterojunction materials such as $\mathrm{MoO}_{\mathrm{x}}{ }^{30}, \mathrm{nc}_{-} \mathrm{SiO}_{\mathrm{x}}{ }^{31}$ and $\mu \mathrm{c}-\mathrm{SiC}^{32,33}$.

Table 1 Comparing the potential of conventional SHJ solar cells with TCO and absorbe
\begin{tabular}{crc} 
conducted SHJ solar cells without TCO \\
\hline With indium based TCO & Without TCO \\
\hline Conductance & Mildly better lateral conductance & Lower contact resistivity \\
\hline Optical & TCO parasitic absorption & No TCO parasitic absorption \\
\hline Passivation & TCO plasma damage, can be recovered & Metal diffusion, can be solved \\
\hline Cost & High Indium cost and supply risk & No indium cost and supply risk \\
\hline
\end{tabular}

\section{Conclusions}

In the present work, we demonstrate a SHJ solar cell design substituting the TCO layer by lateral conduction of c-Si absorber. Using only the c-Si bulk for lateral conduction, excellent lateral carrier collection was verified by achieving a fill factor of $80.7 \%$ and a low series resistance of $0.32 \Omega \cdot \mathrm{cm}^{2}$. Metal diffusion into a-Si:H layer was observed in the direct metal/a-Si:H contacts. To inhibit the metal diffusion, an ozone oxidation was performed on the a-Si:H surface, giving rise to an improved open-circuit voltage in TCO-free SHJ solar cells without increasing the contact resistivity. Simulation result shows that by substituting a $40 \Omega / \square$ TCO layer with c-Si absorber conduction, there is only a minor series resistance increase of $0.04 \Omega \mathrm{cm}^{2}$ in SHJ solar cell while there is a gain in current of $1.09 \mathrm{~mA} / \mathrm{cm}^{2}$. Thereby, this work proposes a solution to remove front side TCO in SHJ solar cells. In this design the reliance on indium in SHJ solar cell is relaxed while the design conflict between transparency and conductivity of TCO layers can be avoided.

\section{Methods}

For the fabrication of TCO-free SHJ solar cells, phosphorus-doped n-type c-Si wafers with a resistivity of $1 \Omega \mathrm{cm}$ and a thickness of $170 \mu \mathrm{m}$ were used as substrates. After ozone cleaning and $\mathrm{KOH}$ texturing, a-Si:H (i)/a-Si:H $\left(\mathrm{n}^{+}\right)$and a-Si:H (i)/a-Si:H $\left(\mathrm{p}^{+}\right)$stacks were deposited by plasma enhanced chemical vapor deposition on the front and rear sides of the wafers, separately. To form 
ohmic contacts between a-Si:H $\left(\mathrm{n}^{+}\right)$and metal in the front surface, Ti/Au/Ag stacks were deposited in an electron beam evaporation system with a thickness of 15/15/20 nm, separately. For the rear surface, two kinds of contacts were used: 1) a-Si:H $\left(\mathrm{p}^{+}\right)$and sputtered ITO contact, and 2) a-Si:H $\left(\mathrm{p}^{+}\right)$and $\mathrm{Ti} / \mathrm{Au} / \mathrm{Ag}$ stacks contact. The metallization was finished by screen printing of Ag paste and curing at $190^{\circ} \mathrm{C}$ for $40 \mathrm{~min}$. The finger pitch of $1.8 \mathrm{~mm}$ was used as in the solar cell. At last, $\mathrm{SiN}_{\mathrm{x}}$ anti-reflection coating was fabricated on the front side of the SHJ solar cells followed by a $200^{\circ} \mathrm{C}$ annealing for $20 \mathrm{~min}$.

In Quokka3 simulation models, n-type silicon wafers with a resistivity of $1.09 \Omega \mathrm{cm}$ and a thickness of $170 \mu \mathrm{m}$ were used. The pitch of fingers was set to be $1.8 \mathrm{~mm}$ which is the same as the experiment. To simplify the simulation, the tunneling transport in the interfaces was not considered in the device. Also, the work function mismatch in the interfaces is omitted and ohmic contact is assumed for all the contacts.

The current density-voltage measurement, electroluminescence image and external quantum efficiency are performed using "LOANA" characterization setup from pv-tools equipped with a SINUS 220 Wavelabs light source. In this work most of the series resistances are extracted by comparing $J-V$ curves under different illumination intensities except for Fig. 4. In Fig. 4 we compare the series resistances under different illumination intensities, so it is important that the series resistances are extracted under that particular illumination intensity. Therefore, we extracted the series resistance in Fig. 4 by comparing the $J$ - $V$ curve in the dark and under illumination.

\section{Acknowledgement}

This work was supported by the HEMF (Helmholtz Energy Materials Foundry) infrastructure funded by the (HGF) Helmholtz association and the German Federal Ministry of Economic Affairs and Energy in the framework of the TUKAN project (grant: 0324198D). The authors gratefully thank Rainer Benczek and his colleagues in Helmholtz Nano Facility (HNF) for the supports in the experiments. The authors also sincerely thank Dr. Andreas Fell for his support with Quokka3 simulation.

\section{References}

1 Battaglia, C., Cuevas, A. \& De Wolf, S. High-efficiency crystalline silicon solar cells: status and perspectives. Energy \& Environmental Science 9, 1552-1576, doi:10.1039/c5ee03380b (2016). 
Werner, S., Lohmüller, E., Maier, S., Mourad, S. \& Wolf, A. Challenges for lowly-doped phosphorus emitters in silicon solar cells with screen-printed silver contacts. Energy Procedia 124, 936-946 (2017). Jäger, U. et al. Benefit of Selective Emitters for p-Type Silicon Solar Cells With Passivated Surfaces. IEEE Journal of Photovoltaics 3, 621-627, doi:10.1109/jphotov.2012.2230685 (2013). Wakisaka, K. et al. in 21th IEEE Photovoltaic Specialists Conference (IEEE, Las Vegas, NV, USA, 1991).

5 Nassar, N. T., Graedel, T. E. \& Harper, E. M. By-product metals are technologically essential but have problematic supply. Science Advances 1, e1400180, doi:10.1126/sciadv.1400180 (2015). Commission, E. Report on Critical Raw Materials for the EU. (European Commission, Brussels, 2017). Frenzel, M., Mikolajczak, C., Reuter, M. A. \& Gutzmer, J. Quantifying the relative availability of high-tech by-product metals - The cases of gallium, germanium and indium. Resources Policy 52, 327-335, doi:10.1016/j.resourpol.2017.04.008 (2017). Richter, A. et al. n-Type Si solar cells with passivating electron contact: Identifying sources for efficiency limitations by wafer thickness and resistivity variation. Solar Energy Materials \& Solar Cells 173, 96-105, doi:10.1016/j.solmat.2017.05.042 (2017). Herasimenka, S. Y., Dauksher, W. J. \& Bowden, S. G. $>750 \mathrm{mV}$ open circuit voltage measured on $50 \mu \mathrm{m}$ thick silicon heterojunction solar cell. Applied Physics Letters 103, doi:10.1063/1.4817723 (2013). Taguchi, M. et al. 24.7\% Record Efficiency HIT Solar Cell on Thin Silicon Wafer. IEEE Journal of Photovoltaics 4, 96-99, doi:10.1109/jphotov.2013.2282737 (2014). Bivour, M., Schröer, S., Hermle, M. \& Glunz, S. W. Silicon heterojunction rear emitter solar cells: Less restrictions on the optoelectrical properties of front side TCOs. Solar Energy Materials and Solar Cells 122, 120-129, doi:10.1016/j.solmat.2013.11.029 (2014). Bivour, M., Steinkemper, H., Jeurink, J., Schröer, S. \& Hermle, M. Rear Emitter Silicon Heterojunction Solar Cells: Fewer Restrictions on the Optoelectrical Properties of Front Side TCOs. Energy Procedia 55, 229-234, doi:10.1016/j.egypro.2014.08.035 (2014).

Haschke, J. et al. Lateral transport in silicon solar cells. Journal of Applied Physics 127, doi:10.1063/1.5139416 (2020). Sawada, T. et al. in Conference Record of the IEEE Photovoltaic Specialists Conference. 1219-1226. solidi (RRL) - Rapid Research Letters 4, 7-9, doi:10.1002/pssr.200903304 (2010).

Rau, U. Reciprocity relation between photovoltaic quantum efficiency and electroluminescent emission of solar cells. Physical Review B 76, doi:10.1103/PhysRevB.76.085303 (2007).

Kirchartz, T. et al. Reciprocity between electroluminescence and quantum efficiency used for the characterization of silicon solar cells. Progress in Photovoltaics: Research and Applications 17, 394-402, doi:10.1002/pip.895 (2009).

Huhn, V. et al. Imaging photocurrent collection losses in solar cells. Applied Physics Letters 109, doi:10.1063/1.4971266 (2016).

Aberle, A. G., Wenham, S. R. \& Green, M. A. in 23th IEEE Photovoltaic Specialists Conference (IEEE, Louisville, KY, USA, 1993).

O'Sullivan, B. J. et al. Process-Induced Degradation of SiO2 and a-Si:H Passivation Layers for Photovoltaic Applications. IEEE Journal of Photovoltaics 4, 1197-1203, doi:10.1109/jphotov.2014.2326711 (2014).

Shockley, W. \& Read, W. T. Statistics of the Recombinations of Holes and Electrons. Physical Review 87, 835-842, doi:10.1103/PhysRev.87.835 (1952).

Hall, R. N. Electron-Hole Recombination in Germanium. Physical Review 87, 387-387, doi:10.1103/PhysRev.87.387 (1952).

Mette, A. New Concepts for Front Side Metallization of Industrial Silicon Solar Cells Doctoral degree thesis, University of Freiburg, (2007).

Fell, A. A Free and Fast Three-Dimensional/Two-Dimensional Solar Cell Simulator Featuring Conductive Boundary and Quasi-Neutrality Approximations. IEEE Transactions on Electron Devices 60, 733-738, doi:10.1109/ted.2012.2231415 (2013). Fell, A., Schön, J., Schubert, M. C. \& Glunz, S. W. The concept of skins for silicon solar cell modeling. Solar Energy Materials and Solar Cells 173, 128-133, doi:10.1016/j.solmat.2017.05.012 (2017).

Fell, A. \& Altermatt, P. P. Detailed 3D full-cell modeling in Quokka3: Quantifying edge and solder-pad losses in an industrial PERC cell. AIP Conference Proceedings 1999, 020007, doi:10.1063/1.5049246 (2018). 
27 Demaurex, B., De Wolf, S., Descoeudres, A., Charles Holman, Z. \& Ballif, C. Damage at hydrogenated amorphous/crystalline silicon interfaces by indium tin oxide overlayer sputtering. Applied Physics Letters 101, doi:10.1063/1.4764529 (2012).

28 Chen, H.-L. et al. A 19.9\%-efficient ultrathin solar cell based on a 205-nm-thick GaAs absorber and a silver nanostructured back mirror. Nature Energy 4, 761-767, doi:10.1038/s41560-019-0434-y (2019).

29 Holman, Z. C., Descoeudres, A., De Wolf, S. \& Ballif, C. Record Infrared Internal Quantum Efficiency in Silicon Heterojunction Solar Cells With Dielectric/Metal Rear Reflectors. IEEE Journal of Photovoltaics 3 , 1243-1249, doi:10.1109/jphotov.2013.2276484 (2013).

30 Dréon, J. et al. 23.5\%-efficient silicon heterojunction silicon solar cell using molybdenum oxide as holeselective contact. Nano Energy 70, doi:10.1016/j.nanoen.2020.104495 (2020).

31 Qiu, D. et al. Front contact optimization for rear-junction SHJ solar cells with ultra-thin n-type nanocrystalline silicon oxide. Solar Energy Materials and Solar Cells 209, doi:10.1016/j.solmat.2020.110471 (2020).

32 Kohler, M. et al. Optimization of Transparent Passivating Contact for Crystalline Silicon Solar Cells. IEEE Journal of Photovoltaics 10, 46-53, doi:10.1109/jphotov.2019.2947131 (2020).

33 Pomaska, M. et al. Transparent silicon carbide/tunnel $\mathrm{SiO} 2$ passivation for c - Si solar cell front side: Enabling Jsc $>42 \mathrm{~mA} / \mathrm{cm} 2$ and iVoc of $742 \mathrm{mV}$. Progress in Photovoltaics: Research and Applications, doi:10.1002/pip.3244 (2020). 


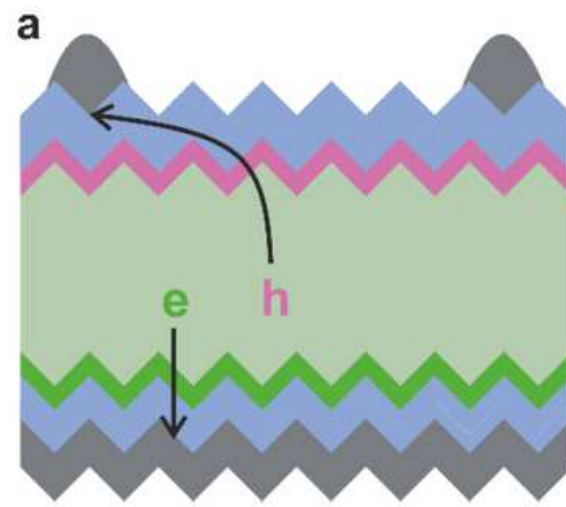

TCO

a-Si:H $\left(\mathbf{p}^{+}\right) / a-S i: H(i)$

c-Si (n)

a-Si:H (i)/a-Si:H (n+)

metal contact b

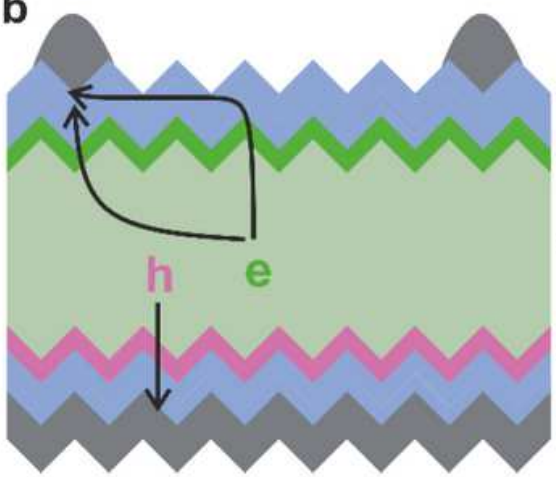

TCO

a-Si:H (i)/a-Si:H (n+

c-Si (n)

a-Si:H $\left(\mathbf{p}^{+}\right) / \mathrm{a}-\mathrm{Si}: \mathrm{H}(\mathrm{i})$

metal contact

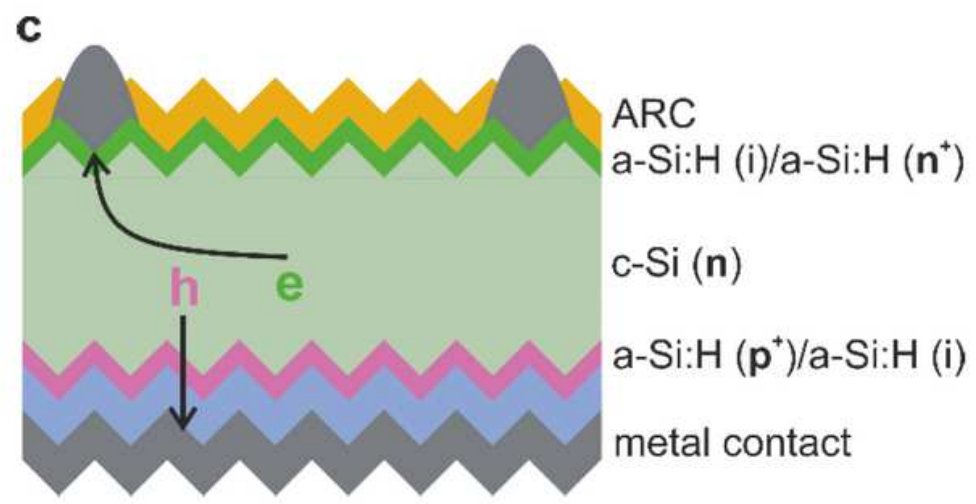

\section{Figure 1}

Illustration of different SHJ solar cell structures and the path for charge carriers to electrodes. a, Sketch of conventional SHJ solar cell structure with a front emitter. b, Conventional SHJ solar cell structure with a rear emitter. c, Rear emitter SHJ solar cells using only the absorber for lateral conduction. SiNx layers are used in the present work as anti-reflection coatings (ARC).
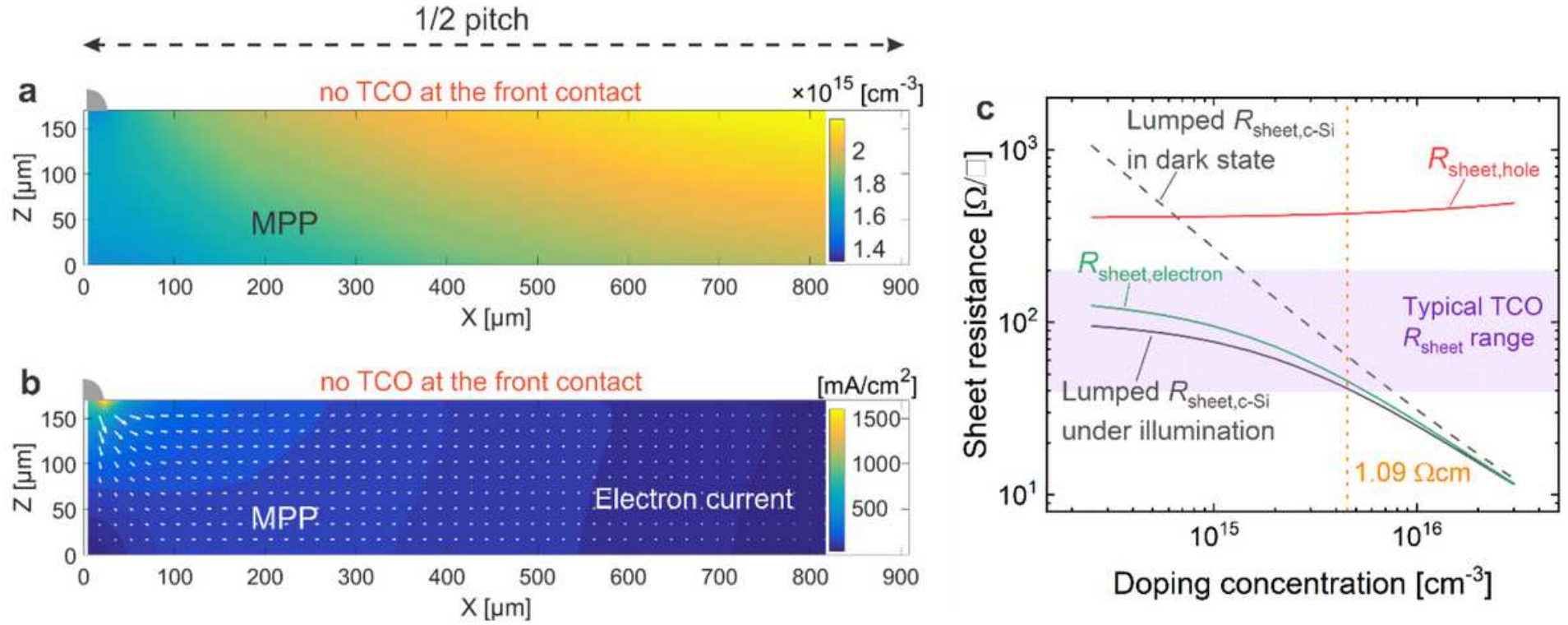

Figure 2 
Carrier transport in c-Si bulk. a, Cross-section image of one-sun excess carrier distribution $(\Delta n=\Delta p)$ in a rear junction SHJ solar cell without front side TCO layer at maximum power point. b, Cross-section image of electron current density in a rear junction SHJ solar cell without front side TCO layer under one-sun illumination at maximum power point. c, Sheet resistance of phosphorus doped c-Si wafer with a thickness of $170 \mu \mathrm{m}$. The dashed line indicates values without illumination and the solid lines indicates values under illumination. The excess carrier concentration under illumination is set as $2 \times 1015 \mathrm{~cm}-3$, which is estimated from fig. 2a. The silicon wafer resistivity is $1.09 \Omega \mathrm{cm}$ in this work which is marked by the dotted line. These results show that majority carriers (electron) are ready for lateral collection in the cSi bulk. 


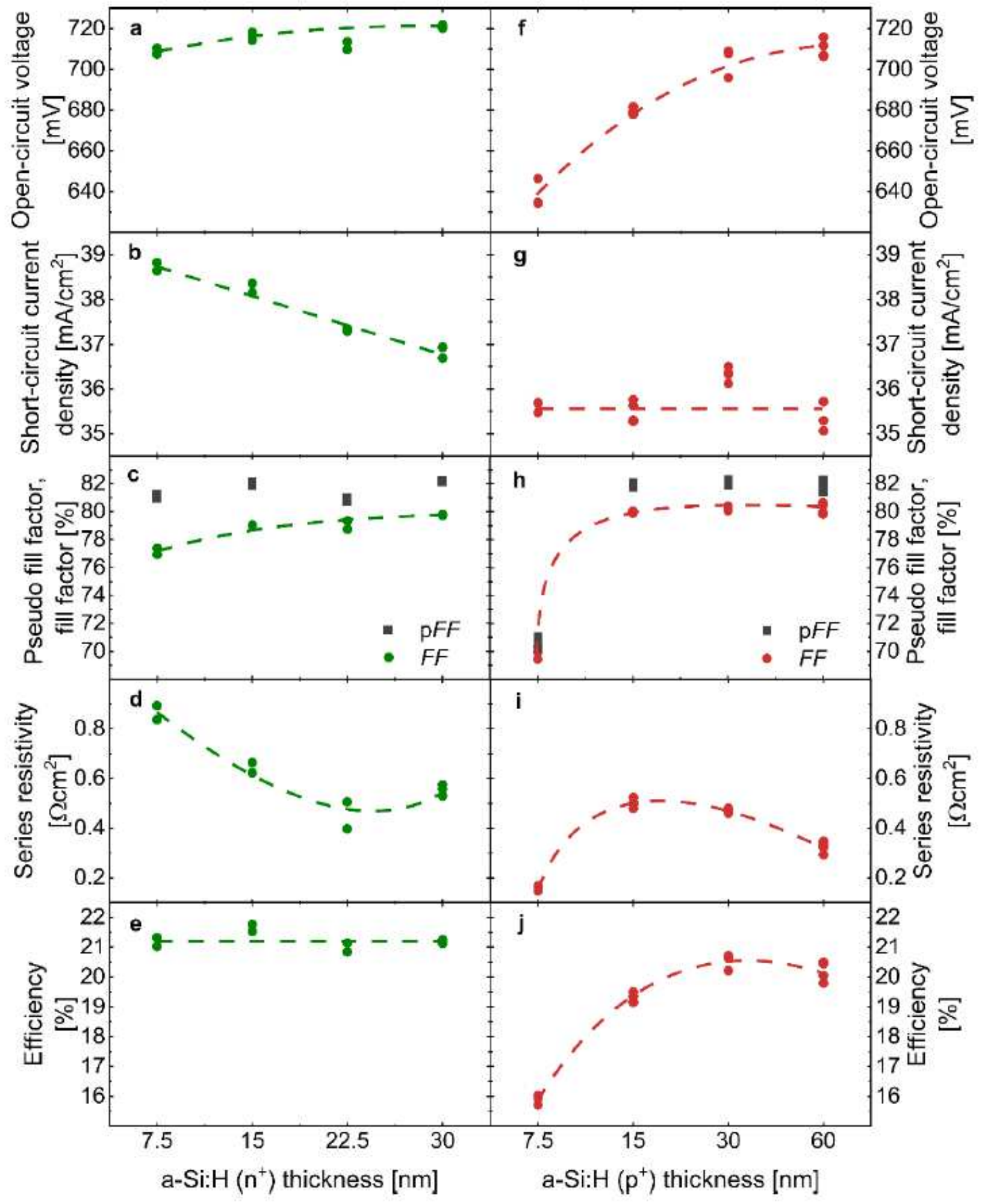

Figure 3

Performance of SHJ solar cells without TCO as lateral conduction layer. a-e, Front side TCO-free solar cell performance with different a-Si:H $(n+)$ layer thicknesses. $f-j$, Both side TCO-free solar cell performance with different a-Si:H $(p+)$ layer thicknesses. For both side TCO-free solar cells, the a-Si:H $(n+)$ layer thickness was $15 \mathrm{~nm}$. The dashed lines are guides to the eye. 

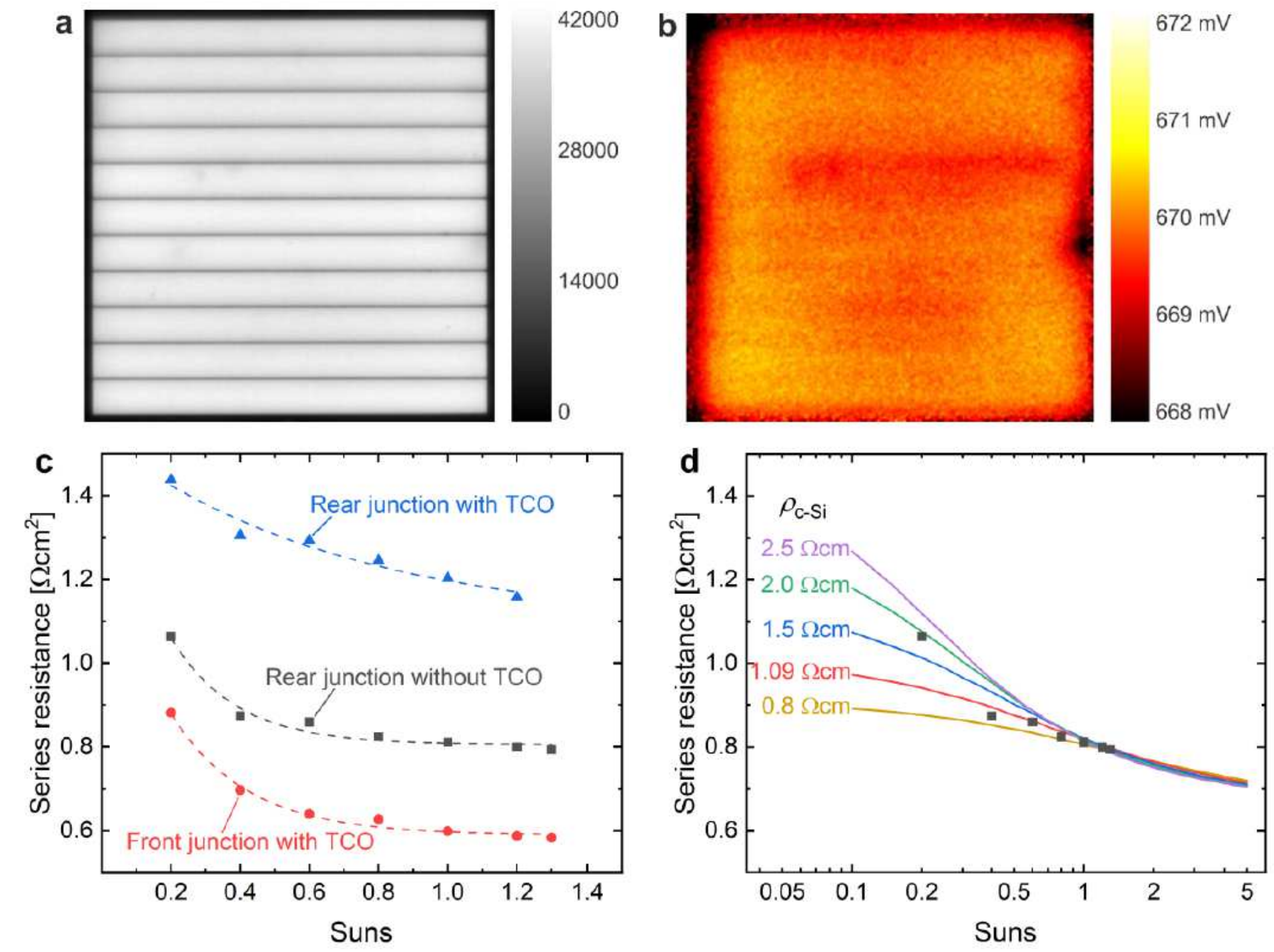

Figure 4

Conduction properties of SHJ solar cells without TCO front contact. a, EL image of a front side TCO-free SHJ solar cell. b, Local voltage distribution extracted from EL images. c, Measured series resistance versus illumination intensity for different SHJ solar cells. d, Simulated series resistance versus illumination intensity for rear junction TCO-free SHJ solar cells with different wafer resistivities. The black dots in Fig. $4 \mathrm{~d}$ is the same data as the black dots in Fig. 4c. The simulated series resistance was calculated from the integral of the resistive losses in the model, which is not measurable, while the experimental series resistance was extracted from dark-light $\mathrm{J}-\mathrm{V}$ method19. 

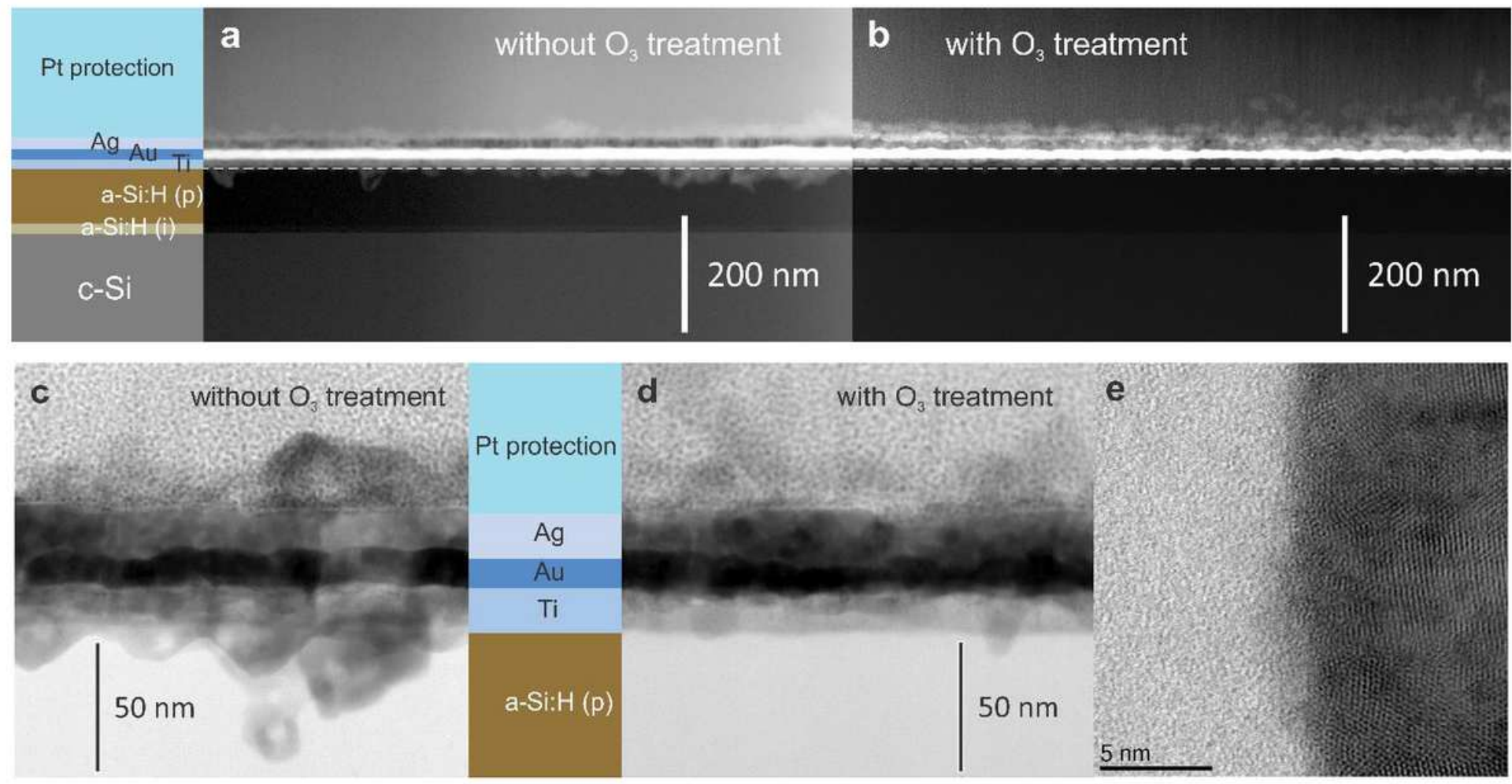

\section{Figure 5}

STEM images of the metal and a-Si:H interfaces. a-b, Dark field (DF) image of metal/a-Si:H interface without and with ozone treatment. c-d, Bright field (BF) image of metal/a-Si:H interface without and with ozone treatment. e, High-resolution BF image of metal/a-Si:H interface with ozone treatment. The STEM images show that metal diffusion leads to passivation deterioration when there is no buffer layer such as TCO in the metal/a-Si:H contact. However, an ozone oxidation on the a-Si:H layers before metallization prominently restricts the metal diffusion in the metal/a-Si:H contact.
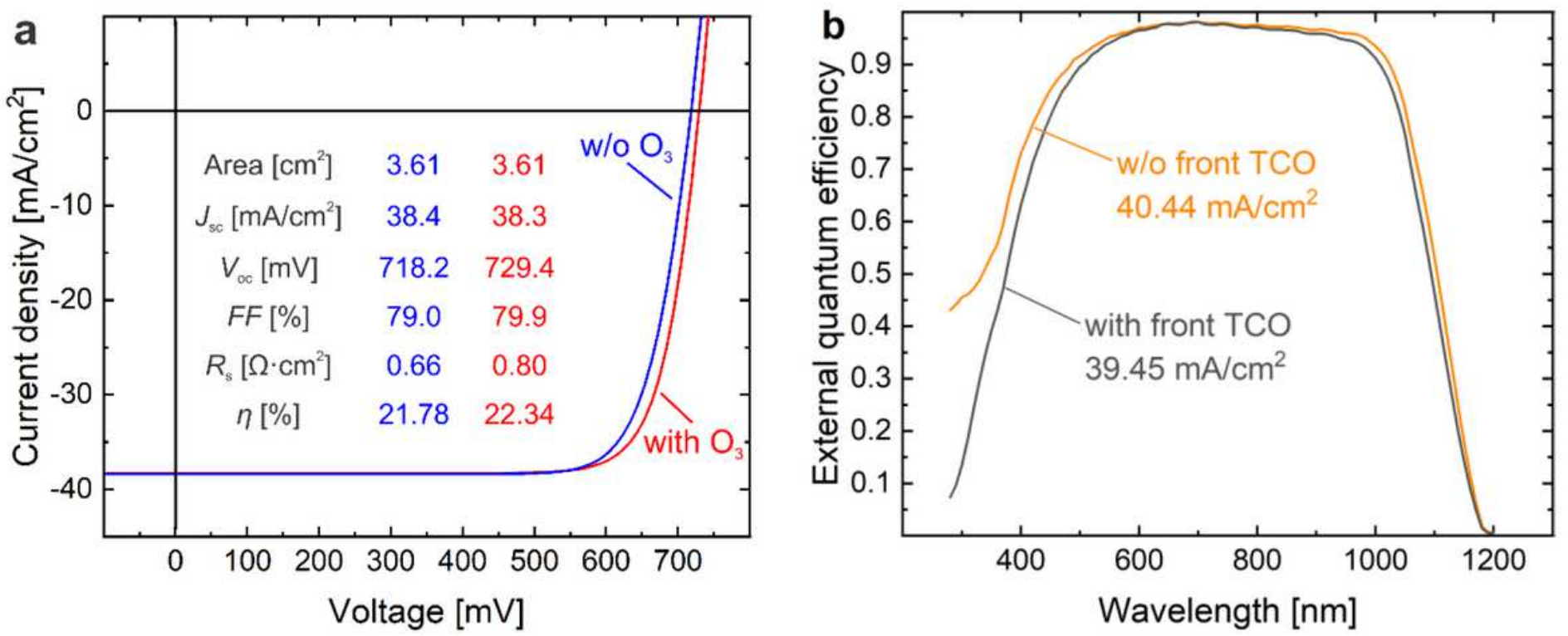

Figure 6 
Characterization of front side TCO-free solar cells. a, Comparison between J-V performance with and without $\mathrm{O} 3$ oxidation as metal diffusion barrier. b, External quantum efficiency comparison between frontside TCO-free solar cells and standard SHJ solar cells with front TCO. It should be noted that the a-Si:H(n) layer thickness is $15 \mathrm{~nm}$ for fig. $6 \mathrm{a}$ and $7.5 \mathrm{~nm}$ for fig. $6 \mathrm{~b}$. An improved external quantum efficiency is shown by removing TCO layer in the front side, giving rise to an increase of $1 \mathrm{~mA} / \mathrm{cm} 2$ in current density.
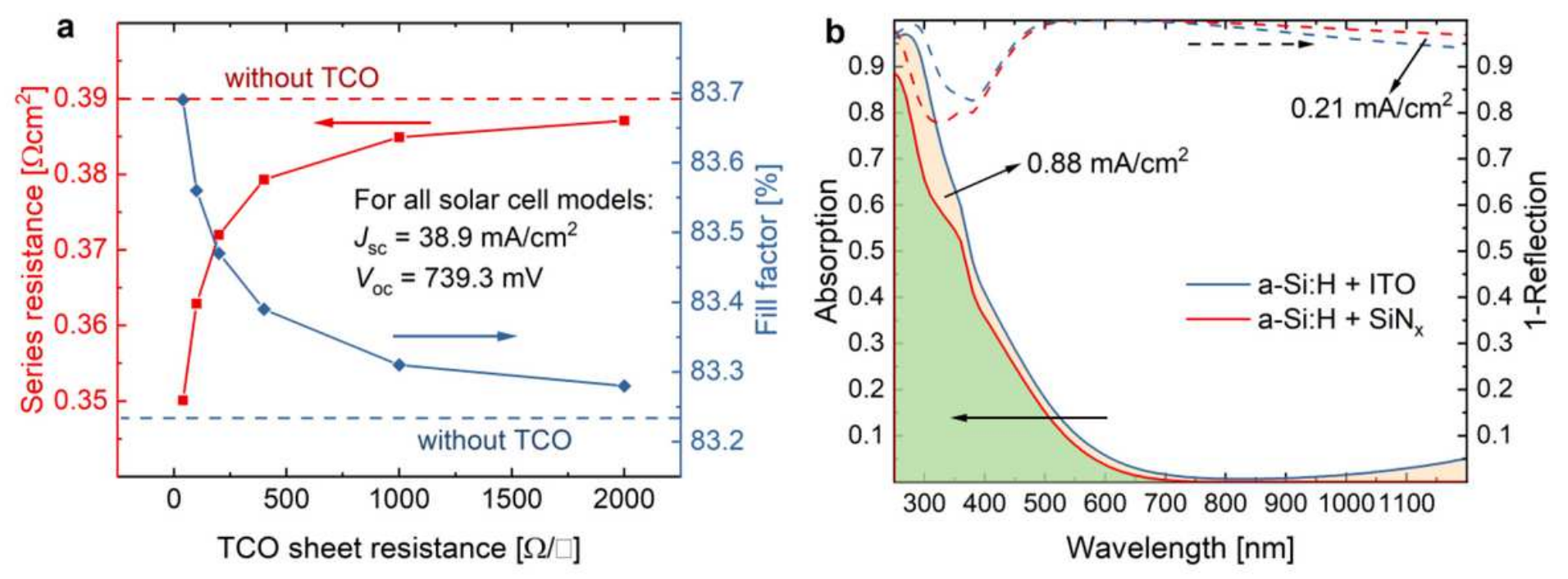

Figure 7

Comparison for SHJ solar cells with and without front-side TCO. a, Simulated performance of rear junction SHJ solar cell with and without front TCO. Solar cell performances with different TCO sheet resistance in the front surface are shown in dots and solid lines. The solar cell performances without front side TCO are shown by the dash line. The optical performance, surface passivation qualities and metal contact resistivities were kept the same with and without TCO to focus only on the lateral electrical transport properties. b, Simulated absorption and 1-reflection spectra using ITO and SiNx as antireflection coating, respectively. By replacing ITO with SiNx, the absorption loss is reduced by $0.88 \mathrm{~mA} / \mathrm{cm} 2$ and the reflection loss is reduced by $0.21 \mathrm{~mA} / \mathrm{cm} 2$.

\section{Supplementary Files}

This is a list of supplementary files associated with this preprint. Click to download.

- SupplementaryinformationTCOfreeSHJsolarcell.pdf 